\title{
Can the subaltern 'speak' science? An intersectional analysis of performances of 'talking science through muscular intellect' by 'subaltern' students in UK urban secondary science classrooms
}

\author{
Louise Archer ${ }^{1}$ D Effrosyni Nomikou ${ }^{1} \cdot$ Ada Mau $^{1} \cdot$ Heather King $^{2} \cdot$ Spela Godec $^{1}$. \\ Jennifer DeWitt ${ }^{1} \cdot$ Emily Dawson $^{3}$
}

Received: 28 June 2017 / Accepted: 8 May 2018 / Published online: 3 October 2018

(c) The Author(s) 2018

\begin{abstract}
This paper draws on Judith Butler's concepts of intelligibility and identity as performance to make sense of enactments of 'subaltern' (that is, subordinated) urban students within secondary school science. Understanding classrooms as constituted by complex power struggles for voice, authenticity and recognition, the paper offers an in-depth exploration of a particular dominant performance of science that was enacted across classes by some students - and which curtailed the possibilities for other students in terms of who can, and cannot, be intelligible in school science. Analysing data from 9 months of observations conducted with nine teachers and c. 200 students aged 11-15 from six London schools and 13 discussion groups with 59 of these students, a dominant performance was identified across the classrooms of 'talking science through muscular intellect'. This was predominantly enacted by a small group of working-class boys from a range of ethnic backgrounds and was generally recognised as an authentic and legitimate performance of science by both teachers and other students. These performances comprised three main elements: competition; dominating and controlling class science talk; and policing the science talk of others. However, such performances were experienced ambiguously by teachers and were viewed negatively by Other students, notably girls and 'quiet' boys, due to silencing their contributions and limiting the range of ways that Others might be recognised as intelligible science students. The paper concludes by reflecting on the implications of the dominance of performances of 'talking science through muscular intellect' for students, teachers and social justice approaches to science education.
\end{abstract}

Keywords Urban students $\cdot$ Judith Butler $\cdot$ Discourse $\cdot$ Power $\cdot$ Gender

Lead editor: Bal Chandra Luitel.

Louise Archer

1.archer@ucl.ac.uk

Extended author information available on the last page of the article 


\section{Science, power, inequalities and the exclusion of 'subalterns'}

In her influential 1988 essay, 'Can the subaltern speak?', Gayatri Spivak poses a dilemma for critical researchers, such as those committed to promoting equity within school science, namely that academic attempts to 'give voice' to the Other are doomed to 'fail' because they inevitably — albeit often unwittingly — reproduce relations of inequality, by homogenising the Other and leaving unequal power relations unaltered. Indeed, Spivak challenges whether elitist academic discourse can ever be an effective critical tool, in that it classifies and surveys the Other, thus reproducing the unequal power relations that it seeks to dismantle. In this paper, we use Spivak's challenge as an orientation point for an exploration of power and the conditions of intelligibility for urban student subjectivities within UK secondary science classrooms. An intersectional lens is employed to foreground how "the colonized subaltern subject is irretrievably heterogeneous" (Spivak 1988, p. 79), within an exploration of the complexities of power and subordination within and across urban students' performances of science. That is, the paper seeks to identify how, and if, diverse urban students can 'speak' science, or not.

\section{Science, elitism and exclusion}

Our interest in this area is driven by a social justice concern to make science a more equitable and accessible field for urban young people. As research by organisations such as the AAUW (2010) in the US, and researchers such as Emma Smith $(2010,2011)$ in the UK have shown, across most western nations the general profile of a 'typical' graduate or professional in the physical sciences or engineering remains White, male and middle-class. Concerns have long been expressed that the dominant culture of science remains persistently White, male and middle-class, as exemplified by the classic work of Sandra Harding (1998). In more recent years, studies have drawn attention to how, within many science classrooms, underserved students feel marginalised and excluded in schools and universities. For instance, Mary Atwater (2000) discusses how many Black American students experience low teacher expectations and are denied equitable opportunities to engage with science, as the dominant culture of science assumes a white norm and marginalises issues of class, language, religion and other axes of oppression.

The literature draws attention to the multiple inequalities and injustices that urban students may encounter through their experiences of science education, including their exclusion by dominant forms of language and racialized and gendered power relations. For instance, Nancy Brickhouse, Patricia Lowery and Katherine Schulz's (2000) paper followed four middle-school girls over time, tracing how their engagement and identification with science was shaped by the possibilities that were opened up, or closed down, by dominant school science cultures and the extent to which these overlapped with, or were in opposition to, the girls' developing gender and cultural identities. Likewise, our own research with underserved students in the UK has also highlighted how Black students' disidentification from science is produced by the white, male, middle-class dominant culture of science (e.g. Archer, DeWitt and Osborne 2015).

As discussed in Eileen Parsons' (2014) review of the literature on race, ethnicity and science education, science education has not traditionally foregrounded issues of equity and social justice and efforts to develop more equitable and inclusive approaches have tended to call for more attention to be given to the role of culture and ethnicity within students' experiences of science education. For instance, Chris Emdin (2010) has pioneered and championed the teaching of science through Black cultural expressions such 
as hip-hop, drawing attention to how such genres are deeply personally meaningful and can facilitate student engagement with science, while also challenging dominant representational regimes, in terms of how science is represented, broadening messages about how science is done and who it is 'for'.

Many governments (as signalled, for instance, by reports by the UK's House of Lords in 2012 and the U.S. President's Council of Advisors on Science and Technology in 2010) underline the importance of increasing science participation to meet national economic imperatives. We, however, consider that achieving more equitable participation in science is desirable on many fronts, most important of which is a social justice agenda, in which broadened and increased science participation operates as a tool for improving social mobility, agency and active citizenship through high levels of public scientific literacy. As we argued in a previous paper (Archer et al. 2015a, b), we see science education as an important form of symbolic capital that can be mobilised to facilitate agency and the reproduction of relations of subordination and privilege. Hence we consider it a social justice imperative to find ways to disrupt, and make more equitable, current patterns of participation in science.

\section{Conceptualising 'intelligibility' and 'identity as performance'}

For our conceptual framework, we draw on the feminist poststructuralist work of Judith Butler (1990). In particular, we employ Butler's concepts of intelligibility and identity as performance to make sense of the performances of 'subaltern' (i.e. underserved) students within secondary school science. We borrow the term 'subaltern' here but with the conceptual understanding that these are not pre-existing, stable subjectivities, but are rather as subjectivities that are produced, negotiated and contested through discourse.

We treat gender and other social identities as being produced through discourse. Rather than being the fixed products of biological bodies, we see gender, ethnicity and all other identities as being constantly re-made and performed-that is, they are never finished and are 'always in process', as Stuart Hall puts it (1990, p. 222). Subjectivities are thus constituted within and through discourse and relations of power. In this way, we see the performance of identity as both an expression, and a mediation, of the extent to which a student may see science as being 'for me', or not.

We understand identity (comprising gender, ethnicity, social class and so on) as, what Butler terms, 'performance'. To exemplify this position using the case of gender: gender is not the 'result' of a person's sex and does not simply follow 'naturally' from particular sexed, racialised, classed, etc. bodies. Rather, Butler argues that gender is socially constructed through discursive and bodily 'acts'. In this respect, gender is not what we 'are' but is rather something that we 'do' (i.e. perform) and continually re-do. Yet the repeated performance of gender creates the 'illusion' that gender is stable and 'real'. Moreover, as Becky Francis (2007) argues, these performances of masculinity and femininity are often diverse and plural, varying across axes of social identity and inequality, such as ethnicity and social class. In other words, there is no single set of performances that constitutes gender (or likewise ethnicity, social class, etc.), rather there may be a plurality of ways of 'doing boy' or 'doing girl', mediated by other intersecting axes of identity, such as social class, age, ethnicity, disability and so on.

As a wealth of research attests, science classrooms, like any site, are not neutral spaces but are constituted through power relations. They are produced through constant negotiations and struggles for voice, authenticity and recognition-that is, who can and 
does, or does not, have voice and authority. As Heidi Carlone and colleagues discuss in their 2014 paper, these contestations work at multiple levels regarding, for instance, who is, or is not, recognised as being 'good at school science', who can produce legitimate science discourse and who can thus be recognised as being a 'good' or 'bad' student. These struggles for authenticity are inflected by intersections of gender, ethnicity and social class which, as Carlone et al. (2011) explicate, result in different teachers creating different conditions within their classrooms for what, and who, is valued as being 'smart at science', or not. Carlone et al. illustrate this point through the poignant example of an African American girl who was able to be recognised as performing herself scientifically in Ms. Wolf's 4th grade class, but not in Mr. Campbell's 6th grade class.

As Jennifer Adams and Preeti Gupta (2017) discuss, identity is responsive to context, hence 'interactions between people are important to identity construction' (p. 4). That is, they suggest, 'our power to act, within certain structures and corresponding affordances, mediates our identity development' (Adams and Gupta 2017, p. 5). Teachers can play a key role in shaping what identity performances are dominantly valued and celebrated, or not, within science classrooms and the implications of these celebrated subject positions for the voice and participation of underserved students. In this paper, we extend our focus to consider the ways in which racialised and gendered enactments of identity, voice and power between students can also play a part in restricting who can 'speak' in the science class.

Although identity is performed, this does not mean that it is freely chosen. That is, while agency is possible, the extent to which a person's identity performances are possible and recognised by others will be constrained by factors such as the body of the actor and by the social field-for instance, what is valued, recognised as authentic and 'allowed' (i.e. 'intelligible'). That is:

the "coherence" and "continuity" of "the person" are not logical or analytic features of personhood, but rather, socially instituted and maintained norms of intelligibility" (Butler 1990, p. 23).

We find Butler's notion of 'intelligibility' to be a particularly useful tool for exploring urban students' identity performances within science because it foregrounds the social pressures that students may experience to conform to particular dominant norms. That is, an intelligible identity performance is one that can be read as valid because it re-inscribes and supports particular dominant, normative values and relations within a given context. Thus, identity performances which are subversive or challenging of dominant identities and practices within the science classroom will be 'unintelligible' and will be seen as 'out of place' by those in authority, potentially attracting disapproval, sanctions and even fear or disgust. As Butler explains, the cultural matrix through which identity becomes intelligible "requires that certain kinds of "identities" cannot "exist"" (Butler 1990, p. 24). Hence, we are interested in the extent to which urban students are able to perform intelligible identities within a field (in this case, the science class) that is dominantly inscribed as high status, White, male and middle-class.

We understand performances of identity as taking place within what Nigel Edley and Margaret Wetherell (1995) term an 'ideological battlefield', in which different actors compete for authenticity, voice, recognition and dominance. Not all identity performances carry equal power: the more powerful, or hegemonic, performances are those which claim dominance and status and which are often based on the disavowal, negation and oppression of Other, less powerful, identities. For instance, Raewyn Connell (1989) explains how a common feature of hegemonic masculinity is its discursive organisation 
around the subordination of Others, notably women and gay men. For instance, a key performance that has been identified within educational contexts is that of 'muscular intellect', which involves confident, arrogant displays of knowledge and 'intelligence', which has been noted particularly among some high-achieving middle-class boys by Mairtin Mac An Ghaill in his 1994 work and by Becky Francis and colleagues in their 2012 study of high attaining popular school students.

However, not all students will be able to authentically enact hegemonic performances such as muscular intellect. Intersections of gender, ethnicity and class can structure these possibilities in powerful ways-for instance, the close association of muscular intellect with masculinity may make it more difficult for girls to perform in any sustained or authentic way. Equally, among boys not all performances of hegemonic masculinity will necessarily be 'successful'-for instance, they may be resisted or contested by others and the authenticity of the performances may be called into question.

In this paper, we ask:

- What were the most socially and scientifically powerful, dominant student identity performances in the classrooms? Who performed these and why and how were they intelligible?

- How were these performances experienced by students and teachers?

- How were the performances disrupted?

Through our analysis and discussion we also sought to identify and reflect on what the implications of these performances might be for students' science engagement and participation.

\section{Research in schools}

In line with the theoretical framework explicated above, this paper adopts a feminist poststructuralist epistemological perspective. In other words, 'reality' is understood as relational and socially constructed through discourse. However, we do not take a strong relativist position, in which all competing accounts and interpretations of reality are accorded an equal 'weight'. Rather we adopt a weak relativist epistemology, drawing on an intersectional feminist political commitment to what Susan Bordo (1990) termed 'baseline realities', that enables us to identify, name and challenge inequalities such as sexism, racism and classism (as 'real'), while also recognising the social construction and performance of racialized, gendered and classed identities and inequalities. From this perspective, reality is understood as socially constructed, but some discursive constructions and performances are recognised as being more powerful (e.g. oppressive or liberatory) than others. Moreover, from this position, we conceptualise the effects of inequalities as being experienced in 'real' (discursive and materially meaningful) ways.

The data reported in this paper were generated over the course of a 9 months research and development programme that was conducted with nine teachers from six inner London schools as part of a longer, 5 years Enterprising Science study. The wider study comprised a partnership between universities (University College London and King's College London), the Science Museum and the funder (BP). The wider project involved three main, different strands of work but findings reported in this paper came from the research arm of the third strand, which sought to examine the social and cultural factors that shape student 
engagement with science within classrooms. Three of the participating schools (Coleville, Mareton and Northfields - all pseudonyms) are state-run, co-educational schools which, at the time of the researcher, recorded within $\pm 20 \%$ of the GCSE results of other schools within their local area (GCSE's (General Certificate of Secondary Education) are series of exams students take in the UK when they are 16). The schools had relatively high proportions of students who spoke English as a second language and were registered as eligible for free school meals, compared to other schools in the same region. Schools were purposively sampled to include high proportions of from communities that are traditionally under-represented in science and who have lower levels of 'science capital'-a concept that we have previously developed and described elsewhere (Archer et al. 2015a, b). In each of these three schools we worked with two teachers who taught at least one class in the 11-16 age range (Key Stage 3 and Key Stage 4). The other three participating teachers, who taught at three different schools, had all taken part in a professional development course that had been conducted in one of the two preceding years, as part of one of the earlier phases of the project (details of which can be found in King et al. 2015). These teachers had all expressed an interest in being involved with future phases of the project. Details on the participating teachers and their classes are provided in Table 1.

As detailed in Table 1 , the sample comprised a spread of year groups $(1 \times \mathrm{Y} 7$ class, $3 \times \mathrm{Y} 8,3 \times \mathrm{Y} 9$ and $2 \times \mathrm{Y} 10)$ and attainment (set or track) groupings ( $4 \times$ bottom set, $2 \times$ middle set and $3 \times$ top set). With the exception of students in Ms. Smith's school, students were predominantly from working-class and a range of minority ethnic communities. The most frequently spoken languages across the student sample were Urdu, Bengali, Turkish, Polish and Portuguese.

In this paper we draw primarily on data from field notes of classroom observations and discussion groups with students. Fieldwork was conducted by the research team (who are listed as paper authors), all of whom are middle-class women and of whom four are White British, two are White European, one is White American and one is British Chinese. Our conceptual position rejects any simplistic distinction between 'emic' and 'etic' (insider/ outsider) positions within ethnographic fieldwork. Following Nancy Naples (2003, p. 8), who argues that 'ethnographers are never fully outside or inside the 'community', we understand power relations between researchers and participants as complex and negotiated, 'flowing' in myriad ways during any research encounter, albeit with the overall balance of power tending to remain in favour of the researcher, who predominantly has the privilege of framing, interpreting and representing the research process. Our intersectional approach also complicates any simplistic notion of researcher-participant 'matching' (e.g. by intersections of gender, ethnicity, social class, age, region, dis/ability, and so forth). Although we recognise that differences in the (multiple) structural positionings and experiences between researchers and participants will inevitably have implications for the social construction of the research process and the interpretations and knowledge produced. While there is no simple or fixed formula that determines, as Diane Reay puts it, what differences our differences make within the research process, we agree that it is useful for researchers to reflect on the potential implications of the knowledge and interpretations we produce, not least with regard to the representation of Others (see discussion). 


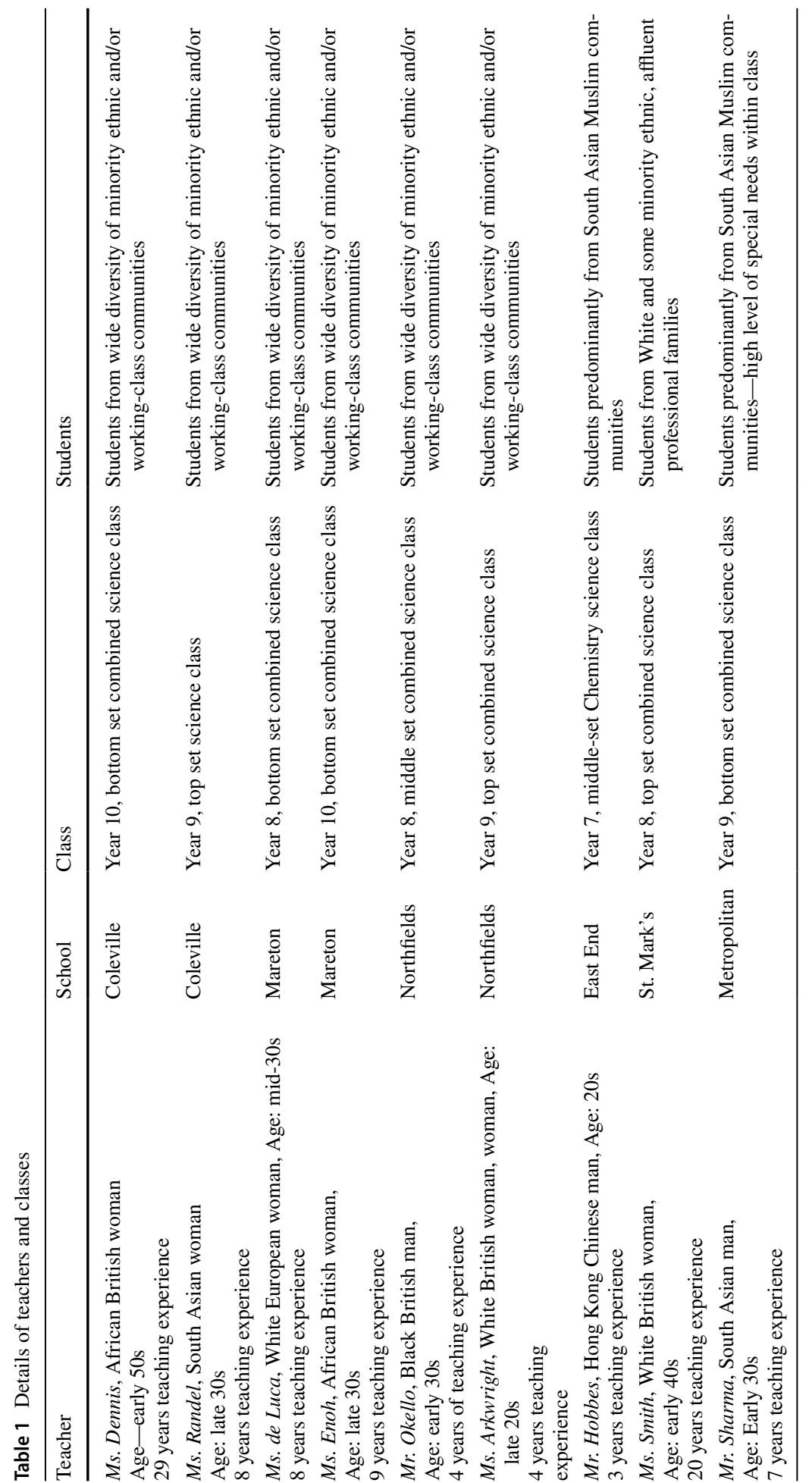




\section{Working in classrooms}

\section{Observations}

Each class was observed by one or two researchers over the 9 months period (September 2015 to June 2016). Researchers attended classes approximately every 2-3 weeks over this period. Researchers typically sat at the back or the side of the classroom and recorded field notes either by hand (using pen and paper) or on a lap top computer or iPad. Observations were guided by an ethnographic-inspired approach, attempting to capture 'rich' descriptions of the classrooms, including how students behaved, what they were doing during the lesson, what they said, how they interacted with the teacher and peers and whether they appeared to be engaged with particular aspects of the lesson, or not. While we did not use a formal 'check list', the research team did spend time before the observations discussing the various aspects of the classroom that we might want to capture and our understandings of what constitute 'thick' descriptions. For instance, we agreed, where possible, to try to capture group dynamics (e.g. which students we interpreted as being more or less dominant), bodily gestures and movements, facilitation from teachers and the content of student discussions as well as other events of note. Given the complexity that we were seeking to capture, we also tried, where possible, to have two researchers in the room (one focusing on the teacher and one focusing on the students), in order to generate as rich field notes as possible and to allow for us to explore differences in interpretation between researchers.

In this paper, we present and discuss our researcher-led interpretations of what we observed and what teachers and students from these classes told us in interviews and discussion groups about their experiences. This is not to imply that we are adopting a positivist position, whereby we accord our interpretations the status of being a window on some objective reality. Nor do we follow a strong relativist position of seeking to elicit and present (without researcher interpretation) a range of participant-driven articulations of their experiences in these classes. Rather, we adopt a sociological analytic approach, which formulates a theoretically-informed/driven interpretation of both our observations and the experiential accounts of participant teachers and students that were produced by the socially constructed research process. The goal of this interpretive exercise is to identify and unpick some workings of power that we feel may have social justice implications. For instance, our approach means that we may accord a different value to one set of performances and articulations (e.g. those that we, as researchers, interpret as 'sexist') compared to another set. Moreover, our interpretations may not accord with the views of all our participants (e.g. some students recounted experiencing these particular performances as oppressive, whereas others, but notably those performing them, did not). However, we offer our interpretations as 'just' interpretations, albeit interpretations that attempt a degree of transparency in that they make explicit the conceptual assumptions that have been brought to bear within their construction.

\section{Discussion groups}

Towards the end of the field work period (April-May 2016) 13 discussion groups were conducted with 59 students - see Table 2. The aim of these groups was to elicit students' experiences and views on their science classes and on our emergent analytic themes. For instance, we identified particular examples from the lessons and asked the students for their views and experiences of these- - such as, what they had thought of this topic and the way 
it was framed, what they had liked or disliked about it. We also asked which students they considered to be a 'science person', or not, and the reasons why. We also asked about student participation within classes (e.g. do all students contribute equally in class, or not?) and specifically probed for students' views on gender dynamics, which included asking students' views on some of our specific interpretative observations (for instance, where we had noticed that girls tended to speak less often and less confidently in a specific class). Although we sought to conduct discussion groups with each teacher's class, this was not possible in every instance. Discussion groups were conducted in a quiet space, usually an empty classroom, during class time and varied in length between $20 \mathrm{~min}$ and $1 \mathrm{~h}$, depending on the time available. Potential student discussion group participants were identified and grouped by teachers, dependent on parental consent to participate.

\section{Ethics}

Consent for student and teacher participation was obtained from school managers and personal consent was obtained from all teachers prior to the commencement of fieldwork. Parental and student consent was obtained to collect, report and use the data for participating students. While we made efforts to obtain informed consent (e.g. taking time to explain the research process to students and making clear how their data would be used and treated) it should be noted that very few students had prior experience of much knowledge of social scientific research and some students had to interpret the forms for their parents. While we did seek to use the teacher interviews and the student discussion groups to share-and get participants' views on-our emerging interpretations, the timings and scope of the project precluded any meaningful attempts to co-construct knowledge with participants. Hence authorial power remained with us, as researchers, and the interpretations we offer are made from our partial and privileged perspective as researchers.

\section{Analysis}

In line with our theoretical framework, we understand identity performances as combining talk, gestures, embodiment and behaviours. Analysis of the field notes and discussion group audio transcripts was carried out by the lead author, followed by a secondary checking by all the other authors.

The lead author undertook the analysis, as detailed below, which involved an initial theory-driven search of the data (guided by the question, what were intelligible and unintelligible performances within the classrooms?) The coded examples arising were then explored comparatively (e.g. to what extent were these examples similar or different and agreed upon, or contested, between different data sets and contexts-for instance, did students in the discussion groups agree or disagree with teacher accounts and researcher observations?). Analyses were conducted through an iterative process of moving between the data and theory. The final analyses and coding were checked by all authors. Following an ethnographic approach to qualitative data analysis, themes were interrogated as to their prevalence within the data, convergent and divergent examples were explored and data were analysed in relation to the three data sets. Where there were examples of divergence, we have attempted to make this clear in our reporting - for instance, we have written previously about how what teachers said that they valued (as student performances of science identity) did not always tally with what we observed in classrooms nor with what students reported that they thought their teachers valued (see Archer et al. 2017). 


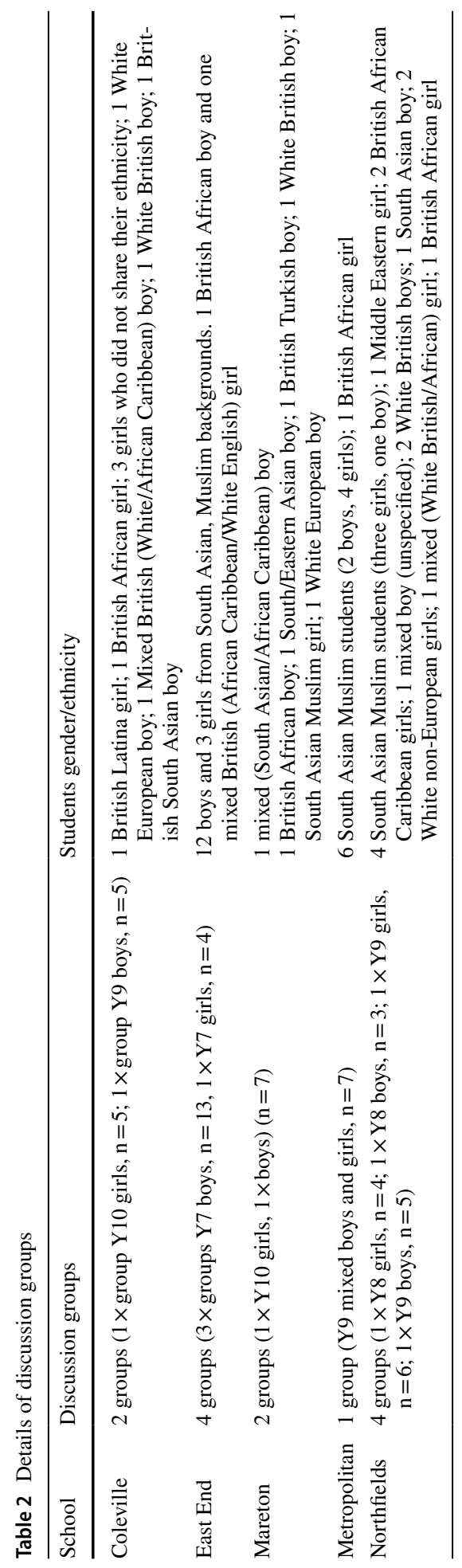


Data were then analysed using a discourse analytic approach informed by a Butlerian conceptualisation of gender identity as performance, as discussed earlier. As Erica Burman and Ian Parker (1993) discuss, discourse analytic approaches differ from more general approaches to discourse analysis, in that they do not attempt a close, 'micro' textual analysis but rather look for patterned talk (i.e. discourses) within the data. A key feature of a discourse analytic approach is looking for how power is organised within talk and drawing out the social implications of particular constructions. In other words, our analysis asks: What is the talk 'doing'? What is being normalised or defended? Where is the locus on power within a particular construction-whose interests are being asserted? Who or what is being othered? What is normalised or closed down? As explained above, while our analyses attempt to take seriously the voices and views of our participants, our discourse analytic approach is very much a researcher-led analysis. Hence, following numerous discourse analytic researchers, such as Margaret Wetherell and Jonathan Potter (1992), the paper reflects and privileges the researchers' interpretations and representations of the discourses at work within our participants' talk, rather than participants' own interpretations per se.

We began by searching the data to identify examples of when teachers and students described or performed 'intelligible' and 'unintelligible' performances - that is, behaviours and talk that were valued and sanctioned as 'good' or appropriate ways of doing science and those performances that were silenced, marginalised, criticised or complained about by others and that was positioned as inappropriate or 'wrong' ways of being in the science classroom. This process identified two main intelligible performances. The first comprised performances of 'good student' identity, which—drawing across the observations, teacher interviews and student discussion groups - coalesced around students being behaviourally compliant with school rules, putting their hands up to answer teacher questions, talking science, completing their work in a timely and conscientious manner and being generally docile and supportive of the authority of the teacher. However, as discussed later, data from the observations and discussion groups suggested that these 'good student' behaviours were not always recognised by teachers and students as authentically 'scientific' and hence intelligible.

The second performance was one that we interpreted as being a more powerful, dominant performance, which we termed 'talking science through muscular intellect'. This performance involved students asserting both social and scientific dominance in a range of ways, and was widely recognised as a legitimate (if not, the most legitimate) performance of science. It was performed particularly during teacher-centred, whole class discourse (often during question and response segments of the lessons). However it was also noted as being performed during small group discussions (e.g. boys calling out and interrupting other groups' discussions or trying to get the teachers' attention while they facilitated a different small group) and during the (very infrequent) times that classes engaged in practical work (e.g. shouting out the 'answers' to the teacher or other students while they were meant to be engaged in personal or small group hands on inquiry). It is this performance of 'talking science through muscular intellect' that we focus on in this paper.

We sought to unpick the constituent elements of this performance, producing three main features of the performance: competition; controlling class talk; and policing class talk. To identify talking science through muscular intellect as a performance of 'masculinity', we used Becky Francis' (2000) gender binary tabulation, which details the traits dominantly associated with masculinity and femininity within contemporary British culture and maps out the relational nature of these traits. For instance, Francis' details how talk, practices and resources that are organised around public displays of competition are dominantly 
configured as performances of masculinity and how talk and practices associated with nurturing and childbirth are dominantly configured as feminine. Finally, we searched the data to identify instances of how other students experienced and constructed performances of talking science through muscular intellect and identified any instances when performances of talking science through muscular intellect appeared to be disrupted or challenged.

\section{Performances of power and dominance-'talking science through muscular intellect'}

Our analysis surfaced more than one intelligible identity performance across the nine science classrooms, however, the most dominant (i.e. that which was identified across observations, interviews and discussion groups and which achieved significant visibility, power and 'voice' within the classes as both a high status performance of science and a socially powerful identity performance) was a performance that we termed 'talking science through muscular intellect'.

As Jay Lemke (1990) discusses, 'talking science' is widely recognised as an authentic, institutionally recognised and valued way of doing science. Likewise, as discussed above, performances of 'muscular intellect' have been identified as powerful, dominant ways of performing masculinity within educational and intellectual contexts. We observed that when students combined these two performances (that is, talking science through the performance of muscular intellect), it resulted in a particularly potent exercise of power that was recognised by both teachers and students.

'Talking science through muscular intellect' was characterised by confident, often 'arrogant', competitive displays of using 'correct' scientific terminology, often in the context of verbal 'one-up-manship' and as part of bids for public voice and attention within the classroom. We identified these performances as characterised by three main elements (i) controlling and dominating classroom science talk, (ii) competitive performances of talking science and (iii) policing and regulating what counts as legitimate science talk and the disparagement of other ways of engaging, doing and speaking science.

(i) Controlling and dominating class science talk

Mika tells the rest of the class to be quiet and listen to Miss. He explains how you can calculate the power in the lightbulb using the equation (Ms. Dennis, $9^{\text {th }}$ December)

Mr. Hobbes is facilitating the girls to answer a question during small group discussion. Youssef [who is in a different group] interrupts and shouts out over the answer that the girls are giving. Qadir calls “sir" repeatedly, trying to get Mr. Hobbes's attention. The girls are trying to ask Mr. Hobbes questions about electricity but the boys keep interrupting their group discussion and trying to get his attention instead so they can give their own answers (Mr. Hobbes, $9^{\text {th }}$ February).

Mr. Hobbes asks the class "what are we talking about today?" Casey shouts out "acidic, acidic stuff". Dwayne and Ahmad are sat quietly with their hands up. Mr. Hobbes says "we are going to start with acids today. The opposite of acids is -?" Qasim shouts loudly “alkaline!” Casey repeats “alkaline” (24 ${ }^{\text {th }}$ February) 
The selected extracts illustrate how the boys in question use particular discursive strategies to claim control of the classroom science talk. In the first extract, Mika raises his voice and instructs the whole class to be quiet and to listen to the teacher-an act which, in itself, can be interpreted an assertion of dominance due to Mika's adoption of a prototypical teacher role. He then goes on to claim the discursive space, speaking instead of the teacher and giving an appropriately scientific explanation of the question that the class is meant to be addressing. This move asserts and bolsters his legitimacy as someone who is appropriately scientific and has the authority to 'speak'. Had Mika's scientific explanation been produced, say, in response to a question from the teacher, we might have coded it as example of 'talking science', but his preceding instruction to the class (to "be quiet" and "listen to miss") and his immediate subsequent claiming of the discursive space (i.e. providing the explanation himself) lead us to read his performance as a discursive manoeuvre which seeks to assert a position of dominance vis-à-vis both his peers and even his teacher.

In the second extract, Youssef (South Asian British Muslim boy) and his friends attempt to wrestle the teacher's attention away from the girls whom Mr. Hobbes was in a small group discussion with, so that they can get their answers heard instead. Youssef and Qadir make repeated bids for recognition which we interpret as attempts to dominate the class science talk space. Again, their efforts are predicated on raising their voices above other students and attempting to gain the focus of the teacher, away from the small group that he is facilitating. Their bid to interrupt the girls' discussion with Mr. Hobbes can be read as an attempt to exercise power in relation to both the girls and the teacher, in that they are contravening the classroom norm that (in this instance) was that students should be discussing the topic in small groups and that interjections require students to put up their hands and wait to be asked to answer a question or make a contribution. As with Mika's example, the boys are not reprimanded for their interruptions and hence their actions can be read as achieving a degree of legitimacy - although they are not entirely 'successful', in that Mr. Hobbes ignores their attempts to interrupt and continues his discussion with the girls.

In the third extract, Casey (a white British working-class boy) shouts out to answer the teacher's question, cutting in ahead of Dwayne (African Caribbean boy) and Ahmad (South Asian Muslim boy). The latter two were widely recognised as 'good' boys in the class, and they had put up their hands to answer the question, in line with the school's behavioural norms, but are usurped by Qasim's interjection. This example also involves a boy raising his voice above others and contravening expected behavioural norms in order to assert his own answers ahead of the two 'good, quiet' boys (Dwayne and Ahmad) who have raised their hands and are waiting to be called on to speak. We interpret this example as constituting a bid for recognition that is achieved through an exercise of power, which seeks to assert the protagonists' dominance within the class science talk space.

(ii) Competitive performances of talking science which dominate class talk and teacher attention

Mr Hobbes is writing an example on the periodic table to exemplify the point he has been making about metalloids. He starts saying "If I have metal on this side and a non-metal on this side..." but Mubid and Ali shout out to interrupt. Mubid calls [loudest]: "a metal that is not actually a metal! Yes!" Mr Hobbes says "it is a good answer" but he says that Ali has given a better answer and tells the class "have a listen". Ali explains "A metalloid is a metal that contains metal like features but is not actually a metal". Mr Hobbes gets him to repeat the answer again for the class and then explains further (Mr. Hobbes, $18^{\text {th }}$ November) 
Mr. Hobbes shushes the class and explains the task. The students have to use a list of scientific keywords to help answer the comprehension task on synthesis and decomposition. They have to work on this in their books and then Mr. Hobbes reviews the answers with the class. Qadir shouts out loudly and abruptly over other boys to give the first answer. [...] Mr. Hobbes invites Qadir to answer the first question for the class. Qadir says "iron and oxygen make rust". Mr. Hobbes confirms the answer and chooses another student to answer the next question, but each time Qadir continues to call out the answer over the chosen students (Mr. Hobbes, $12^{\text {th }}$ January).

Mr. Hobbes has put a photo of a baby pulling a face on the powerpoint screen as the students come in. A question is on the board with the photo: 'what is happening here? Do you like this feeling?' As the class comes in they look at the screen and start discussing the image and question with the person next to them or in small groups. Qasim looks at the screen and shouts immediately at Mr. Hobbes "cos its acidic, that's why!" (Mr. Hobbes, $24^{\text {th }}$ February)

Mr. Hobbes asks Jana to give her answer to the class. He draws a diagram to explain as she answers. But he has to stop as some of the boys are talking over her. Jana starts again, saying "you take out the..." But Casey interrupts. Mr. Hobbes tells Casey not to talk while Jana is talking. Jana starts again "You take out a quarter.." But Ayesha talks over her this time. Jana tries again "And add 1.5 water to the squash..". Mr Hobbes probes her reply says to the class "yes, that is correct". Jana smiles and says "yeah!" The girls celebrate a little but Mubid calls out to them and the class "yeah but Ahmed got it right first!" (Mr. Hobbes, $24^{\text {th }}$ February)

The above extracts, all taken from Mr. Hobbes' class, provide some of the clearest examples of instances in which a small group of boys (namely, Mubid, Ali and Qadir, who are consistently assertive and vocal South Asian Muslim boys, and Casey, a white workingclass boy) compete to shout out the 'correct' answer using scientific terminology. In the first example, Mubid and Ali interrupt the teacher and compete to give their answers first, with Mubid's being the first and louder, and hence more clearly audible, response. Mubid then 'celebrates' his 'win' with a self-congratulatory exclamation ("yes!") Although his interjection is recognised and affirmed by his teacher ("it is a good answer"), Ali 'wins' the competition, in that Mr. Hobbes judges Ali's answer to be 'better', on account of its scientific formulation and expression. He accords it greater symbolic status, calling for it to be rearticulated as an exemplar response for the rest of the class.

As Francis (2000) discusses, competition is a trope that is associated with dominant forms of masculinity and hence is an intelligible way to perform masculinity. Yet it is also sanctioned as a legitimate way to perform science, as illustrated by the boys' competitiveness with one another and Mr. Hobbes' legitimation of the competition by allowing the answers and judging the responses against each other-with Ali's being judged to be 'better'. Indeed, Ali's response is even modelled as an ideal response for the class ("have a listen").

In the next two extracts, Qadir shouts out answers beyond his turn (in the second extract) or when the class are meant to be discussing the question amongst themselves (third extract). Although his answers are not recognised by the teacher, neither are they sanctioned. The fourth extract features Jana's repeated attempts to be allowed to articulate her response to a question that Mr. Hobbes has asked her. She is first interrupted by a group of boys who try to talk over her answer. She is then interrupted by Casey, whose interruption is challenged by Mr. Hobbes, and Ayesha, who Jana talks over to give her reply. When Mr. Hobbes confirms her answer as 'correct', Jana and her friends, including Ayesha, celebrate 
their 'win' - that is, they celebrate having got the answer right. However, Mubid interjects to challenge their 'success', asserting that 'Ahmad got it right first' (i.e. claims he worked the answer out before the girls). In this respect, we interpret the passage as exemplifying how talking science is normalised as a competitive practice-with competition being traditionally aligned with masculinity.

We suggest that these competitive performances can also be read as performances of 'confidence', in that they are assertive, quick, loud and assured public displays. Within the discussion groups, a performance of confidence was frequently linked to performances of science identity. For instance, when asked how someone might be able to identify a 'science person' in their class, students from discussion groups across different schools claimed that "confidence is the key". Confidence was also linked with performances of competitiveness and the assertion of the self in relation to others through talking science. As one student put it, 'being good at science' is popularly recognised as someone "flaunting their, like, knowledge", such as through confident displays of talking science. In this respect, we suggest that competitive performances of talking science through muscular intellect, such as those illustrated above, were intelligible both as performances of science and as performances of masculinity.

As illustrated by the above examples, performances of talking science through muscular intellect were often sanctioned by teachers and students as constituting valid, authentic ways of doing science even when they contravened other norms, such as the behavioural expectation that students should not 'shout out'. We interpret this as a marker of the potential power of such performances. That is, a successful performance enables a student to assert themselves as active and agentic - they are not the 'docile bodies' that Michel Foucault (1980) discusses as the usual product of the school's practices of discipline.

(iii) Policing what counts as 'proper' science talk

Mr. Okello calls on a few students to read out their questions (...) Moira starts her sentence "How do the vibrations, wait ..." [she pauses and looks for her notes]'. Raja speaks abruptly to Moira: 'Come on, say it properly!' (Mr. Okello, $26^{\text {th }}$ February)

Mr. Hobbes asks "Why are wires made out of copper and not gold?" (...) Salma says "cos electricity doesn't flow through it so well?" but she says it quietly and the class are talking. Mr. Hobbes asks her to repeat her answer. Salma blushes slightly, looks down and says "oh, I forgot what I was going to say [pauses] oh, I remember" then repeats her answer. Qadir loudly shouts 'electrons!' at her [in an 'aggressive' tone]. Mr. Hobbes ignores Qadir and follows up with Salma, “ok, so you mean gold is a good conductor". (Mr. Hobbes, $18^{\text {th }}$ November)

Raani asks Mr. Sharma a question about the exercise (working out the number of protons, neutrons and electrons in different elements), saying "Sir, is it that this goes....?" Gabriel repeats what Raani said in a 'silly' (high pitched, 'comic') voice, saying "Is it that, Sir, Is it that sir?" Karam laughs. Raani tuts and rolls her eyes. Mr. Sharma tells Gabriel “don't' be mean” (Mr. Sharma, $7^{\text {th }}$ December)

We observed that performances of talking science through muscular intellect often involved the protagonists performing in ways that we interpreted as mocking or admonishing other students who were unable to produce science talk in the correct register. For instance, as illustrated by the above examples, the three boys in question convey, by shouting or mockery, that another student (in each case, a girl) has not been speaking 'correctly, either by not using the 'correct' scientific terminology (Raja, Qadir) or by not talking in a confident, 
authoritative tone that is often associated with dominant performances of both science and masculinity (Gabriel). For instance, Raja chastises Moira to "say it properly" and Qadir tells Salma the "correct' scientific terminology that he thinks she should have used ("electrons"). Gabriel's imitation mocks the register of Raani's voice-which we interpreted as ridiculing both the femininity of her voice, through a high pitch imitation, and her dependence and lack of confidence (in that she has asked for clarification, assurance and help) - which are set in opposition to his own masculine, confident voice and independent performances of talking science through muscular intellect within the class.

We suggest that the above examples can be interpreted as attempts to 'police' and control the boundaries of what counts as legitimate forms of discourse within the science class. These attempts to control the symbolic order are reinforced through the discipline and punishment (e.g. harassment, telling off, public ridiculing) of students (like Moira and Salma) who do not or cannot conform and perform in the 'correct' way. As Michel Foucault writes, the exercise of power achieves the control of individuals through practices of surveillance and examination, 'to be able at each moment to supervise the conduct of each individual, to assess it, to judge it, to calculate its qualities or merits" (1980, p. 143). In this respect, we interpret the performance of talking science through muscular intellect as a technology of power, which enables protagonists to produce themselves as simultaneously intelligible as both 'scientific' and 'masculine', the dominance and authority of which are achieved through their surveillance and control of other students, as they police the boundary of 'what counts' as being 'appropriate' ways of performing science. That is, they position hegemonic masculinity as a, if not the most, legitimate way in which to perform science. We also note that in each example it is boys who are policing girls' science talk, a pattern that was reflective of our wider observations. We interpret this as due to the 'double alignment' of the performances — not only is masculinity dominantly configured as authoritative over femininity but also, thanks to the dominant alignment of science with masculinity, performances of masculinity are used to police the boundaries of class science talk. However, as we discuss next, it was not all boys, but rather particular boys, who enacted and were intelligible in their performances of talking science through muscular intellect.

Spivak (1993, p. 104) famously argued that 'the subaltern as female cannot be heard or read'. In this respect, we suggest that the boys' performances of talking science through muscular intellect, and their self-appointed 'policing' of other students' voices within the classroom science, can be read as practices of power which seek to control the boundaries of what counts as an authentic performance of science and who is allowed, or not allowed, to speak in class. As such, we understand such performances as being problematic in equity terms. Indeed, we suggest that the dominance of the performance of talking science through muscular intellect was such that the main male protagonists were often observed to close down the validity of girls' voices at all within the science classes.

\section{Who was intelligible, or not, in their performances of 'talking science through muscular intellect'?}

While a range of boys and girls from diverse ethnic backgrounds were observed 'talking science' across the classes, only a small group of boys were observed performing intelligible and legitimated performances of 'talking science through muscular intellect'. In line with the classroom populations of the urban classrooms being observed, these boys were 
from working-class and predominantly minority ethnic communities. For instance, Raja is an African British working-class boy; Qadir, Mubid, Gabriel and Youssef are all British South Asian Muslim working-class boys; and Casey is a white British working-class boy. Although, as discussed further below, not all the boys' performances were 'successful' (that is, not all their enactments of talking science through muscular intellect were recognised as legitimate by others), on the whole, these students were regularly observed as making consistent, loud, public bids for recognition through their performances of talking science through muscular intellect, asserting themselves in relation to both teachers and students.

They were not the only students to attempt such performances, but they were the only students whose attempts were consistently successful. The 'success', or not, of such attempts seemed to relate to the embodiment of the student in question, as girls were particularly unlikely to have their attempts at such performances recognised. For instance, our observations indicated that, across the classes, the symbolically dominant performance of talking science through muscular intellect did not appear to be an intelligible performance for girls. Most girls did not attempt performances of talking science through muscular intellect. For instance, even Boudica (a mixed White British- African Caribbean girl, Ms. Arkwright's class), who was recognised by other students in her class as being very smart at science-and is recorded as receiving among the highest marks in the class-is rarely recorded in field notes as speaking out in class and offering her view. A couple of girls did attempt the performance, but none were observed to be 'successful' at it. For instance, the following example was typical of Sadia's repeated attempts to call out the correct answers to her teacher's questions:

The class are checking through their answers on their worksheets. Sadia (South Asian girl) continues calling out responses to most of the questions. But Ms. Dennis never responds - she neither disciplines Sadia nor values her responses. Sadia calls out again, 'Insulin!' Ms. Dennis finally responds - 'Insulin, don’t shout.' (...) Ms. Dennis puts up an image of insulin and Sadia calls out the answer, reading out the description from the book. Ms. Dennis ignores her and asks the class "what do we call people who have problems controlling their blood sugar?" One student offers 'sickle cell anaemia' and another 'diabetes' (Ms. Dennis, $3^{\text {rd }}$ February)

In the above example, Sadia arguably attempts to perform talking science through muscular intellect: she calls out the 'correct' answer ("insulin") and she attempts to talk science by giving the 'correct', 'official' description of insulin from her school text book, a strategy that she attempts a couple of times during the class. However, her performances are largely ignored and, in contrast to the previous examples (e.g. with Mubid, Ali and Qadir), Sadia is told off by Ms. Dennis for shouting out ("Insulin—don't shout"). This sanction contrasts with the various examples discussed above in which boys who shouted out as part of their performance of talking science through muscular intellect, were not told off.

The legitimacy of a performance of talking science though muscular intellect also depended on being able to 'get the answer right'. Hence students who attempted it but who provided 'incorrect' answers, were unlikely to be recognised as performing authenticallywith failed attempts attracting peer ridicule. For instance, during a discussion on discerning between compounds and mixtures, Mr. Hobbes used a cooking analogy to spark discussion:

Mr. Hobbes asks "if I put all the ingredients in the pot and start cooking, apart from the steam and all those lovely smells that come out, does anything else escape the pot?" There is lots of excitement and students shout out answers. One boy shouts out "water". Another boy shouts "Bacteria!" A few of the boys stop calling out and turn instead to 
the boy who shouted it out, saying "what, man?!" (with a tone of incredulity and amusement) (Mr. Hobbes, $11^{\text {th }}$ November).

We suggest that attempting performances of talking science through muscular intellect can be a potentially risky endeavour, albeit one in which the chances of 'success', and the potential for asserting dominance that this produces, is increased by the possession of particular cultural and embodied resources. For instance, the boys who regularly achieved 'successful' (i.e. legitimated, sanctioned) performances of talking science through muscular intellect held in common (i) a 'masculine' body and performances of popular, 'laddish' masculinity (e.g. most performed loud, popular, 'jokey' masculinity—none of the boys were read as performing what Connell (1989), terms effeminate or 'wimpish' masculinity) and (ii) were confident in their knowledge of science and displayed a proficiency in being able to talk science. Where students lacked one or both of these aspects, they were much less likely to produce, and be read as successful in producing, performances of talking science through muscular intellect.

\section{How are these performances intelligible and how are they disrupted?}

We understand the intelligibility of the boys' performances of talking science through muscular intellect as derived from the way in which they combine normative performances of both science and masculinity. The performances are intelligible as performances of science because they involve talking science and conform to popular notions, as expressed by students in the discussion groups, that 'being sciencey' requires 'got a lot of knowledge about science' (Alexis, Black African Y10 girl) and actively demonstrating this knowledge within the class ('answering all the questions' and not 'being quiet'). The performances are intelligible as masculinity because they involve prototypical masculine assertions of authority, 'voice' and control, as read through Francis' gender binary, and also overlap with masculinised norms of ideal student participation as being 'active', as opposed to passive.

In one respect, the boys' performances of talking science through muscular intellect might be interpreted as surprising and transgressive, in that we might expect that dominant performances of science 'should' be unintelligible for students from working-class and/or minority ethnic backgrounds, given the white middle-class dominant culture and coding of science. That is, we might expect those who occupy subordinated positions in terms of ethnicity and social class, to find it harder to enact dominant, powerful legitimated performances of science. As such, the above examples might be interpreted, to some extent, as moments of 'empowerment', in that they show 'subalterns', who are traditionally 'underrepresented' within science participation, being recognised for their performances of science. As Foucault proposes, power is productive, not just repressive, and as such the boys' performances of power could be interpreted as using masculinity-which could be their only axis of privilege - to resist and push back against their classed and racialized positions of subordination.

The performances are also potentially surprising in that they entail 'subaltern' students asserting power in relation to their teacher-contravening both general 'good student' behavioural norms and indeed, the norms that many of the students in discussion groups themselves asserted as key to performance of being scientific, such as 'putting your hand up to answer questions' in class. In this respect, the performances might also be read as confounding notions of the total 'powerless' or silenced subaltern subject-or, again, exemplifying how the exercise of disciplinary power by schools also produces resistance. The data might also be read as examples of how students can use science as a discursive 
resource and space through which to do different forms of identity work, as powerfully exemplified in Angela Calabrese Barton and Edna Tan's 2010 study of agency, identity and science learning among urban middle-school youth.

The boys' performances thus confound readings of themselves (as working-class, minority ethnic young people) as 'unable to speak' in science, as they assert a strong presence and 'voice' in the classrooms and their contributions are usually recognised by teachers and other students as being 'scientific'. However, as discussed further below, we also read these performances as problematic due to their enactments of power in relation to other students which simultaneously curtailed other students' intelligibility and 'voice'.

\section{How are performances disrupted?}

Although some boys were observed making reasonably regular and consistent 'successful' performances of talking science through muscular intellect, these performances were not always guaranteed or legitimated. Antonio Gramsci (1971) argued that hegemony is never absolute and always entails spaces and moments of resistance. Likewise, the boys' performances of power were enacted within discursive limits and were sometimes disrupted. We categorised these disruptions as taking place when boys were unable to maintain intelligibility in their performances-notably, when they did not, or were not able to, perform 'talking science'. For instance, we noted a few instances when boys were unable to maintain the intelligibility of their own performance in this way:

The teacher asks for a student to volunteer the answer to the next question. Qadir answers, but it is wrong. He seems surprised and shakes his head and speaks out loud to the class 'Oh! [pause] I thought it was a mixture, a cake mixture'. Other students tut and say 'oh come on, man' (Mr. Hobbes, $18^{\text {th }}$ November)

Here, we read the disruption as being produced through Qadir getting the answer to the question 'wrong'. As discussed above, an intelligible performance of talking science through muscular intellect depends upon a successful performance of talking science (e.g. 'getting the answer right'). Hence in this moment, Qadir's performance is disrupted and becomes unintelligible. This disruption might also be read as signalled through Qadir's slight public embarrassment and disappointment, as his usual loud confident tone falters slightly, and he attempts to publically explain away his 'error' ("oh [pause] I thought it was a mixture"). We interpret Qadir's example as illustrative of how the performances are precarious, in that they are only intelligible to the extent that the actor can maintain getting answers 'right'. This suggest that this imperative is underscored by the close association of both dominant masculinity and science identity with the notion of being 'smart' and 'clever', an association that our previous work suggests is highly prevalent across students (see Archer and DeWitt 2017).

We also noted instances of performances being disrupted when they crossed the boundary of intelligibility for student behaviour and were sanctioned by teachers. For instance, to revisit the previously cited extracts from Mr Sharma's and Mr. Hobbes' class:

Gabriel mocks her (copying her voice) saying "Is it that, Sir, Is it that sir?" Karam laughs. Raani tuts and rolls her eyes, as if used to this from the boys. Mr. Sharma tells Gabriel “don't' be mean" (Mr. Sharma, $7^{\text {th }}$ December) 
Jana starts again "you take out the..." But Casey interrupts. Mr. Hobbes tells Casey not to talk while Jana is talking. (Mr. Hobbes, $24^{\text {th }}$ February)

On these occasions, the teacher sanctions, rather than legitimises, the boys' performances. We suggest that this may be because the performances are not sufficiently intelligible as 'talking science' and hence slip into being intelligible only as performances of masculinity, which are attempting to mock and/or silence other students, specifically girls in each of the above cases. In this configuration, the performances are rendered unambiguous contraventions of expected behavioural norms (e.g. not being 'mean' to others; not interrupting others) and hence the boys are told off. We also noted similar instances of when other students admonished performances of dominant masculinity that did not involve talking science. For instance, telling the boys in question to 'shush' and be quiet:

Qadir is throwing stuff, Kaleem tells him to stop but $\mathrm{m}$ throws a pen lid at him too.

Mr. Hobbes counts down for quiet. Casey also shouts "shush" and various boys on the front row do the same shush. [...]

Qadir calls out loudly to one of the girls, "Muslim! What would you do?" He continues shouting loudly at the girls. Kaleem shouts loudly at Qadir "shush! Can you just shush? We are going to be late for lunch" (Mr. Hobbes, $18^{\text {th }}$ November)

Finally, we noted a small number of instances when other students 'spoke back' to challenge and disrupt boys' performances of talking science through muscular intellect. For instance:

Qadir and Salma are still needling each other. He keeps saying to her "you're dumb".

Salma retorts 'oh if I'm dumb how can I speak?' (Mr. Hobbes, $18^{\text {th }}$ November)

In this extract, Qadir's insult can be read as working in two ways-both of which position Salma as an unintelligible voice within the science class. First, the use of 'dumb' signifies a lack of intellect, which sits in opposition to dominant performances of talking science through muscular intellect, in which intelligibility is predicated on performances of 'braininess'. Second, 'dumb' conveys someone who, literally, cannot speak-and hence has no voice within the science class. Moreover, as discussed earlier, this also sits in tension with performances of talking science through muscular intellect. However, Salma argued back, asserting her own 'voice' (“if I'm dumb, how can I speak?"), challenging the validity of Qadir's attempt to silence her. We interpret such examples as conveying how girls were not solely passive 'victims' of the boys' performances but rather, by 'talking out' and 'talking back', attempt to 'possibilise' themselves, both as agentic young people and as science subjects.

\section{How are these powerful, dominant performances experienced and reacted to by others?}

\section{Teachers-feeling ambiguous}

Our discussions with teachers outside of class time suggested that they found the boys' performances sometimes challenging and difficult to address-both in pedagogical terms, because the boys were assertive and loud students who could challenge the teachers' authority and silence other students, but also conceptually, because the performances were 
ambiguous, that is, they contravened some behavioural norms while also being legitimate to the extent that they were appropriately 'scientific'. The two male teachers who taught the classes in which we recorded the highest frequency of instances of performances of talking science through muscular intellect and the silencing of other students through these, described to the researchers how they sometimes felt at a loss to know how to approach or deal with these behaviours - which, for Mr. Hobbes in particular, was further complicated by the intersection of ethnicity, gender, class and faith.

Mr. Hobbes is a middle-class, Hong Kong Chinese young man, who both identified himself and was identified by his students as performing a 'gentle', 'caring' and 'quiet' masculinity. He worried that, were he to challenge the sexism that he perceived as enacted by some of his South Asian Muslim male students, he might be at risk of being 'culturally insensitive', because he felt that some of the boys' gendered performances might be expressions of working-class, Muslim masculine 'culture'. His concerns were further amplified by the different performances of masculinity between himself, as someone who performed 'quiet', caring, non-dominant performances of masculinity, and the small group of boys who consistently enacted loud, dominant masculinity.

We interpret Mr. Hobbes' dilemma about how to deal with the boys' masculinity performances as exemplifying the complex layers and intersectionality involved in enactments of identity. For instance, the boys' behaviours can be read as intelligible performances of science, hegemonic masculinity, Muslim masculinity and 'ideal' student identity, in that they support dominant educational ideals of the 'active' and 'assertive' student. However, these performances also challenge norms around 'respectful' student interactions and dominant notions of the 'passive' docile, governable student body which is subservient to teacher authority. Moreover, in the context of widening participation in science, the boys' agentic performances of science and their confident claiming of scientific 'voice' might be welcomed as instances of traditionally under-represented students participating in and 'owning' science. Yet at the same time, the performances are problematic in that they are excluding and silencing the science participation of Other under-represented students.

\section{Students-feeling 'bad', 'lesser' and 'silenced'}

In the discussion groups, girls and quieter boys complained that these performances (of what we termed talking science through muscular intellect) made them feel 'bad', 'dumb' and 'stupid'. We interpreted these criticisms as deriving from the way in which talking science through muscular intellect normalises and valorises assertive, aggressive, loud, public and competitive displays of scientific 'intellect' and subjugates alternative ways of talking science, such as quiet, modest, tentative and 'private' forms of discourse, such as small group discussions, which girls and 'good, quiet' boys said they preferred and were observed as engaging in.

In the discussion groups, students identified examples of behaviour, which we coded as talking science through muscular intellect, that they experienced as powerful and oppressive performances. As Sharifa (South Asian Muslim Y8 girl, Mr. Okello's class) put it: "they act like, they're like superior and high bred and all this, better than anyone else". We read Sharifa's comment as particularly interesting due to her hint that these performances are not just 'powerful' ("superior") but also convey a higher social status ("high bred ... better than anyone else"), which we suggest could indicate how the 'middle-class' and elitist connotations of science might 'rub off' and be conferred on those who can 'speak' it in intelligible ways. 
Girls and 'quiet, good' boys in the groups recounted how they felt silenced by performances of talking science through muscular intellect. As Sharifa explained: "the boys are so loud, they're like... they don't let you speak". Likewise, Ahmad (from Mr. Hobbes' class) complained that by cutting in and answering all the questions first, "other people don't get a chance".

\section{Implications-quiet and other students are rendered unintelligible}

As a result of the dominance of talking science through muscular intellect, we suggest that Other performances of science, notably those which were 'quiet', were less likely to be intelligible as 'properly scientific'. For instance, across the discussion groups, students largely described girls as being 'quiet' in science classes and, when asked to identify who the 'science people' in their class were, only one of the thirteen discussion groups spontaneously identified a girl-despite girls often being identified as the highest attaining students in many of the classes. We suggest that students may have had trouble seeing girls as 'science people' because of the dominance of talking science as muscular intellect. For instance:

"Like Claire, she doesn't really contribute to the class. When Miss asks a question, Claire just tells me the answer like quietly, but I don't know why but she doesn't put her hand up. And she knows it's the right answer, but she's never put her hand up to tell the answer, I don't know why" (Bataar, Mongolian Y10 boy, Ms. Enoh's class)

Rohan: Like there's this girl, Liana, in our class - it's like the quiet people usually have a better knowledge, but they don't share the knowledge with the class, yeah (...)

Taheem: Boys, yeah, they are much more loud

Rohan: The women are much quieter and sit at the back, so they don't get chosen most of the time" (Y9 boys, Ms. Randel's class)

As the above extracts illustrate, Bataar and Rohan (mixed White British-African Caribbean boy) 'know' that Claire (White Turkish girl) and Liana (White British girl) respectively are among the most competent science students in their class. For instance, Liana is recognised as having "a better knowledge" than others and Claire "knows the answers'. However, the girls are "quiet" and fail or refuse to perform this knowledge publicly and confidently ("they don't share the knowledge with the class"), hence are not recognisable as an authentic 'science person'. Both Rohan and Taheem (White European boy) align girls ("women") with quietness, which they contrast with boys, who they identify as being "much more loud". Our observations concurred that the combination of "being loud" and "being sciencey" was predominantly achieved through performances of talking science through muscular intellect which, as discussed earlier, were predominantly performed by boys. In other words, we found that the most symbolically recognised performance of 'being scientific'-namely talking science through muscular intellect-was not a performance that was largely open to, or enacted by, urban girls within the classes.

However, it was not just girls who were unintelligible as scientists due to not performing talking science through muscular intellect. 'Quiet' boys such as Zhenyu (a 
working-class, Chinese boy) were also identified as potentially competent, yet unintelligible, science students:

"Cos there's some people like Zhenyu, he's just quiet. He does all the work cos I remember I used to sit next to him, he used to just do the work but he never contributes [...] like he's kind of intelligent, he knows how to do work, but he just doesn't ... he's just a really quiet person in general [...] I'm in his English class - there he answers more questions. He's still one of the silent ones, but he's contributing much more" (Bataar)

Bataar's comments are interesting in that he recognises that 'being quiet' is not necessarily a result of a lack of understanding ("like he's kind of intelligent, he knows how to do work") and because he draws attention to how student "quietness' may vary between subjects ("in his English class.. he answers more questions"). In this respect, we see performances of talking science through muscular intellect as performances of hegemonic masculinity that entail the subordination of other performances of masculinity-and which might be heightened within subjects traditionally aligned with masculinity, such as science.

\section{Reflecting on implications for theory and practice}

In this paper, we identified and sought to unpick a dominant student performance of 'talking science through muscular intellect' that we interpreted as being enacted across nine London urban secondary science classrooms. In line with forms of sociological discursive critique, we attempted to discern how and why this performance was powerful, who enacted it, how it was experienced by others and how it was disrupted and maintained. In this final section, we also reflect upon the implications for social justice orientated approaches to school science.

Lemke (1990) usefully draws attention to how dominant ways of 'talking science' can be exclusionary and narrowing, and in this paper, we highlighted how, in the classrooms we observed, dominant performances of talking science were strongly gendered, being closely aligned with and enacted through performances of muscular intellect. We interpreted these performances as exerting a strong emotional power, particularly for those boys who performed them, demonstrated not least through their vigorous denigration of 'other' ways of being in science. Our analyses of talking science through muscular intellect foreground performances of voice. This perhaps inevitable given that the performance is very much a verbal discursive performance, albeit one that was also enacted by particular bodily performances (such as often standing up to speak and or boys moving around the classroom in particular ways - for instance, getting out of their seats to attract the teachers attention, or physically moving into the space of a girls' small group discussion). However, we wish to underline that this is not to say that we do not recognise the importance of other performances of science which are more materially configured (e.g. which involve embodiment and/or other objects). We suggest that the focus on this dominant verbal performance may be both partly a function of our methodology (relying on fieldnotes and audio recordings, as opposed to using video recordings which may have better captured embodied performances). There is also the possibility that the verbal nature of this dominant performance could point to the continued dominance of the Cartesian dualism within science - the separation of 'mind' and 'body' and the privileging of 'mind' as an authentic 
(and masculinised) signifier of scientific intellect-a point which we are very grateful to one of the reviewers for suggesting.

Stacy Olitsky (2006) discusses how classroom discourse norms can hinder urban students' potential to feel a sense of solidarity with science-a point with which we agree. Yet our analyses also highlighted the contradictory and dilemmatic nature of classroom discourse, in which some dominant forms of science discourse, as exemplified by talking science through muscular intellect, can both facilitate the engagement of some 'subaltern' students-in our case, working-class boys, from a range of ethnic communities, but who possessed particular masculinity capital-while also constraining the engagement of others, notably working-class/minority ethnic girls and 'quiet' boys. We suggest that our data exemplifies Rowhea Elmesky, Stacy Olitsky and Kenneth Tobin's (2006) argument that the expansion of some boys' agency through performances of muscular intellect and masculinity can involve the contraction and truncation of the agency of others, but especially, in our case, of girls and 'quiet' boys, even when these Other students are ostensibly attaining well in science. We conclude that the symbolic dominance afforded to performances of talking science through muscular intellect has particularly negative implications for the engagement of Other students with science:

Our analyses point to a tricky dilemma: the symbolic status afforded in science classrooms to performances of talking science through muscular intellect did seem to facilitate the engagement and the emotional investment of some urban boys with science, notably those with the requisite masculinity capital and investment in hegemonic performances of masculinity. At the same time, these performances also limited, marginalised and silenced others within the classes, notably girls and 'quiet' boys. That is, we need to acknowledge that some youth and some dominant assumptions within science education (e.g. around what constitute authentic ways of doing science) can play a part in silencing and marginalising some underserved students within school science.

Our discussions with teachers also suggested that they too sometimes found these performances complicated and difficult to address. We might speculate that during their own education and schooling, science teachers might have been socialised into recognising talking science through muscular intellect as a dominant performance of science. Moreover, we have little reason to believe that most science teachers will be comfortable with and well-equipped to engage with complex inequalities. The challenges facing urban science teachers in England may be particularly acute in this respect in this respect, given that nationally very little time is allocated within initial teacher education for supporting teachers to understand and engage with social justice issues. Moreover, few science teachers are likely to have been introduced to debates and issues around equality and social justice within the course of their UK science degrees. We thus suggest that many science teachers, but particularly those entering urban schools, may feel ill-equipped to deal with the complexities of identities and inequalities that they will encounter.

To this end, we recommend that more time and resource might productively be allocated within initial teacher education (ITE) to supporting science teachers to understand and reflexively engage with the complexity of student identities and inequalities and to develop more sophisticated understandings and strategies for engaging with these. We suggest that a key aspect of this training must be to equip teachers with a meaningful recognition of racisms, sexisms and other forms of inequality, and the intersection of these, so that they are able to develop 'a more refined understanding of diverse learners' (Adams and Gupta 2017, p. 5) and can identify and challenge complex forms of injustice.

To return to our initial framing and title-can the subaltern speak science?-we conclude that existing conditions can make it very difficult for many students, but particularly 
girls and 'quiet' boys from working-class and minority ethnic communities, to perform and assert an intelligible 'voice' in classroom science. As such, our findings echo those of Carlone et al., who reflect on how their study emphasises "the difficulty of prototypical school science in sustaining and buttressing nonmainstream students' meaningful science trajectories" (2011, p. 863). Yet, our findings suggest that it is not just teachers who control the boundaries and conditions for which identity performances are recognised and can find authentic expression within science classes_other students can also play a key part in these processes.

How can we sensitively, yet justly, challenge inequalities, such as the silencing of Other students through performances of talking science through muscular intellect, while also working to equitably support diverse young people to engage with science? We conclude by reflecting on the implications for social justice science education research and practice with urban youth, asking how might we create conditions that allow 'subalterns', as heterogeneously conceptualised, to 'speak' in science in ways that open up equitable identity possibilities for all youth? Our analyses drew attention to the ways in which science can be used as a symbolic resource by students who are jostling for power, status, visibility and 'voice' within the 'ideological battlefield' of the science classroom. We suggest that the dominant status afforded to performances of talking science through muscular intellect poses a particular problematic for Other students' engagement and negotiations within these spaces, as they close down the range of possible ways that students might be recognised as performing scientifically.

Spivak argues that we cannot 'give voice' to Others but rather we need to create the conditions that allow diverse Others to speak for themselves. One essential component within this task is to recognise that the Other does not speak in a singular voice. Hence, Spivak discusses how attempts to 'give voice' to Indian subalterns within postcolonial theory was always doomed to fail because (i) this theory assumed a homogeneity among the subaltern, e.g. that there is a singular 'Indian female' voice that can be represented and (ii) it relied on western 'experts' to ventriloquize and 'speak for' the Other, thus re-inscribing the Other's passivity and lack of voice. We thus borrow Spivak's argument to propose that a socially just science education needs to focus on creating the conditions that allow for 'polyvocality' and a diversity of legitimated ways of being and doing in science, while also trying to ensure that none of these voices silences others. Yet we also deviate from Spivak's own position in that we do not see the situation as hopeless.

In line with other scholars, we see a useful way forward lying in an opening up of ways of performing, talking, embodying and doing science-while also opening these up for student debate and critique. In a sense, we are supporting Megan Bang and colleagues' (2012) call for multi-vocality in the science classroom, that is, for the valuing of a diversity of voices and ways of doing science. However, we believe that this cannot be achieved through absolute relativism. That is, we do not think it viable to treat all voices as equal. Rather we advocate for a politics of value that can help us to recognise how and where some voices and practices are more powerful than, and oppressive to, others. This is because without this tempering, we are left unable to challenge inequalities.

Moreover, we note that while performances of talking science through muscular intellect were observed across a range of lesson contexts (for instance, during small group discussions and practical work), they were especially prevalent during teacher-led, whole class discussions which used a prototypical 'question and answer' format. We thus hypothesise that, while we do not consider the performances to be a direct product of a particular pedagogy, some forms of more 'traditional' (chalk and talk) pedagogies may be associated with, or facilitative of, more 'traditional' ways of performing science. In other words, we 
raise the suggestion that more progressive and inclusive pedagogies and approaches to science education may promote and support wider performances of science among students.

We suggest that policy-makers might usefully consider integrating equity approaches more seriously and substantially within initial teacher education. Indeed, in the UK, this is a currently a small and paltry aspect of ITE at best. Without it, why should we expect teachers to be equipped with the required understanding and resources to enact equitable practice that can engage with the complexity of power relations?

Finally, we reiterate calls to rethink the dominant culture of science, in which science and ways of being and doing science are aligned with masculinity and specifically, performances of muscular intellect. Of course, this is no mean feat and we turn to Judith Butler for a guiding framework in this endeavour. In particular, we suggest that there may be value in extending Butler's notion of 'queering' to science education. While Butler proposes this concept in relation to gender and sexuality, we believe that it can be usefully extended to think about a socially just approach to science education more broadly. That is, Butler's concept seeks to fundamentally challenge binaries and disrupt the normalisation of dominant ideology. Within science classrooms this could mean 'unfixing' popular ideas around what counts as speaking, embodying and doing science, e.g. disrupting the normalisation of performances of talking science through muscular intellect. This endeavour does not seek simply to assimilate students into science (as per Brown 2004), rather it aims to challenge and change the ways in which science is currently dominantly configured. In this respect, 'queering' science education places plurality and the contested nature of 'culture' centre stage - that is, the boundaries around 'culture' are loosened and recognised as contested and complexly configured through relations of power, both dominance and subordination. Such an approach would require working across multiple axes of privilege and oppression and recognising the contradictions and tensions that will inevitably be generated. It would involve dismantling the privileged status of both 'talking science' and 'muscular intellect', and could require radically rethinking power relations within classrooms. For instance, challenging the distinction between 'teacher' and 'student' and engaging all participants collaboratively in self-reflexive and agentic engagement with the subject knowledge and in the mutual creation of the norms and values that are to be adopted by those participating in the science classroom. It would also necessitate challenging wider patterns of inequity, to level the playing field regarding the nature and scope of what forms of science education are offered to which students. Yet, we also recognise that such an approach is only part of the answer, given that, as Gloria Ladson-Billings and William Tate (1995) cogently argue, approaches that are focused on changing instructional strategies, may have limited impact because they fail to address wider structural inequalities, such as the inequitable distribution of resources between different communities. We offer these ideas to add to and help further stimulate dialogue around what a vision for a social justice approach to science education might look like, and how it might be achieved in practice.

Funding Enterprising Science was a research and development project conducted in partnership by University College London Institute of Education, King's College London and the Science Museum Group, funded by BP.

Open Access This article is distributed under the terms of the Creative Commons Attribution 4.0 International License (http://creativecommons.org/licenses/by/4.0/), which permits unrestricted use, distribution, and reproduction in any medium, provided you give appropriate credit to the original author(s) and the source, provide a link to the Creative Commons license, and indicate if changes were made. 


\section{References}

Adams, J. D., \& Gupta, P. (2017). Informal science institutions and learning to teach: An examination of identity, agency and affordances. Journal of Research in Science Teaching, 54, 121-138. https://doi. org/10.1002/tea.21270.

American Association of University Women. (2010). AAUW annual report. Washington, DC: AAUW.

Archer, L., Dawson, E., DeWitt, J., Godec, S., King, H., Mau, A., et al. (2017). Killing curiosity? An analysis of celebrated identity performances among teachers and students in nine London secondary science classrooms. Science Education, 101(5), 741-764. https://doi.org/10.1002/sce.21291.

Archer, L., Dawson, E., DeWitt, J., Seakins, A., \& Wong, B. (2015a). 'Science capital': A conceptual, methodological and empirical argument for extending Bourdieusian notions of capital beyond the arts. Journal of Research in Science Teaching, 52(7), 922-948. https://doi.org/10.1002/tea.21227.

Archer, L., \& DeWitt, J. (2017). Understanding young people's science aspirations. London: Routledge.

Archer, L., DeWitt, J., \& Osborne, J. (2015b). Is science for us? Black students' and parents' views of science and science careers. Science Education, 99(2), 199-237. https://doi.org/10.1002/sce.21146.

Atwater, M. M. (2000). Females in science education: White is the norm and class, language, lifestyle and religion are nonissues. Journal of Research in Science Teaching, 37(4), 386-387. https://doi. org/10.1002/(SICI)1098-2736(200004)37:4<386::AID-TEA6>3.0.CO;2-M.

Bang, M., Warren, B., Rosebery, A. S., \& Medin, D. (2012). Desettling expectations in science education. Human Development, 55(5-6), 302-318. https://doi.org/10.1159/000345322.

Bordo, S. (1990). Feminism, post-modernism and gender-scepticism. In L. J. Nicholson (Ed.), Feminism/ Postmodernism. London: Routledge.

Brickhouse, N. W., Lowery, P., \& Schultz, K. (2000). What kind of a girl does science? The construction of school science identities. Journal of Research in Science Teaching, 37(5), 441-458. https://doi. org/10.1002/(SICI)1098-2736(200005)37:5<441::AID-TEA4>3.0.CO;2-3.

Brown, B. A. (2004). Discursive identity: Assimilation into the culture of science and its implications for minority students. Journal of Research in Science Teaching, 41(8), 810-834. https://doi.org/10.1002/ tea.20228.

Burman, E., \& Parker, I. (Eds.). (1993). Discourse analytic research: Repertoires and readings of texts in action. London: Routledge.

Butler, J. (1990). Gender trouble, feminist theory and psychoanalytic discourse. In L. Nicholson (Ed.), Feminism/Postmodernism (pp. 324-340). New York: Routledge.

Calabrese Barton, A., \& Tan, E. (2010). We be burnin'! Agency, identity, and science learning. Journal of the Learning Sciences, 19(2), 187-229. https://doi.org/10.1080/10508400903530044.

Carlone, H. B., Haun-Frank, J., \& Webb, A. (2011). Assessing equity beyond knowledge- and skills-based outcomes: A comparative ethnography of two fourth-grade reform-based science classrooms. Journal of Research in Science Teaching, 48(5), 459-485. https://doi.org/10.1002/tea.20413.

Carlone, H. B., Scott, C. M., \& Lowder, C. (2014). Becoming (less) scientific: A longitudinal study of students' identity work from elementary to middle school science. Journal of Research in Science Teaching, 51(7), 836-869. https://doi.org/10.1002/tea.21150.

Connell, R. (1989). Cool guys, swots and wimps: The interplay of masculinity and education. Oxford Review of Education, 15, 291-303. https://doi.org/10.1080/0305498890150309.

Edley, N., \& Wetherell, M. (1995). Men in perspective: Practice, power and identity. London: Prentice Hall.

Elmesky, R., Olitsky, S., \& Tobin, K. (2006). Forum: structure, agency, and the development of students' identities as learners. Cultural Studies in Science Education, 1, 767-789. https://doi.org/10.1007/s1142 2-006-9034-9.

Emdin, C. (2010). Affiliation and alientation: Hip-hop, rap, and urban science education. Journal of Curriculum Studies, 42(1), 1-25. https://doi.org/10.1080/00220270903161118.

Foucault, M. (1980). Power/knowledge: Selected interviews and other writings 1972-1977. New York: Pantheon.

Francis, B. (2000). The gendered subject: Students' subject preferences and discussions of gender and subject ability. Oxford Review of Education, 26, 35-48.

Francis, B. (2007). Postmodern and poststructural theories. In B. Banks (Ed.), Gender and education: an encyclopedia. Westport, CT: Greenwood Publishing Group.

Francis, B., Skelton, C., \& Read, B. (2012). The identities and practices of high achieving pupils: Negotiating achievement and peer cultures. London: Continuum.

Gramsci, A. (1971). Selections from the prison notebooks. London: Lawrence and Wishart.

Hall, S. (1990). Cultural identity and diaspora. In J. Rutherford (Ed.), Identity: Community, culture, difference (pp. 392-403). London: Lawrence \& Wishart. 
Harding, S. (1998). Women, science, and society. Science, 281(5383), 1599-1600. https://doi.org/10.1126/ science.281.5383.1599.

House of Lords, Select Committee on Science and Technology. (2012). Higher education in science, technology, engineering and mathematics (STEM) subjects. London: The Stationery Office Limited.

King, H., Nomikou, E., Archer, L., \& Regan, E. (2015). Teachers' understanding and operationalisation of 'science capital'. International Journal of Science Education, 37(18), 2987-3014. https://doi. org/10.1080/09500693.2015.1119331.

Ladson-Billings, G., \& Tate, W. F. (1995). Toward a critical race theory of education. Teachers College Record, 97, 47-68.

Lemke, J. L. (1990). Talking science: Language, learning, and values. Westport: Ablex Pub. Corp.

Mac An Ghaill, M. (1994). The making of men. Buckingham: Open University Press.

Naples, N. (2003). Feminism and method: Ethnography, discourse analysis and activist research. New York: Routledge.

Olitsky, S. (2006). Structure, agency, and the development of students' identities as learners. Cultural Studies of Science Education, 1(4), 745-766. https://doi.org/10.1007/s11422-006-9033-x.

Parsons, E. C. (2014). Unpacking and critically synthesizing the literature on race and ethnicity in science education. In N. G. Lederman (Eds.), Handbook of research on science education (Vol. 2). Florence, KY: Taylor and Francis.

Smith, E. (2010). Do we need more scientists? A long-term view of patterns of participation in UK undergraduate science programmes. Cambridge Journal of Education, 40(3), 281-298. https://doi. org/10.1080/0305764X.2010.502886.

Smith, E. (2011). Women into science and engineering? Gendered participation in higher education STEM subjects. British Educational Research Journal, 37(6), 993-1014. https://doi.org/10.1080/01411 926.2010.515019.

Spivak, G. A. (1988). Can the subaltern speak? In C. Nelson (Eds.), Marxism and the interpretation of culture (pp. 271-313). Urbana, IL: University of Illinois Press. https://doi.org/10.1007/978-1-349-19059-1_20.

Spivak, G. (1993). Can the subaltern speak? In P. Williams \& L. Chrisman (Eds.), Colonial discourse and postcolonial theory. Hemel Hempstead: Harvester Wheatsheaf.

U.S. President's Council of Advisors on Science and Technology. (2010). Report to the President and Congress-Designing a digital future: Federally funded research and development in networking and information technology. Washington, DC: Executive Office of the President-President's Council of Advisors on Science and Technology.

Wetherell, M., \& Potter, J. (1992). Mapping the language of racism. London: Harvester Wheatsheaf.

Louise Archer is Karl Mannheim Professor of Sociology of Education at University College London, Institute of Education, UK. Her research focuses on educational identities and inequalities, particularly in relation to social class, gender and ethnicity. Her most recent book is co-authored with Jennifer DeWitt, titled Understanding Young people's Science and Career Aspirations (Routledge).

Effrosyni Nomikou is Research Associate at University College London Institute of Education, London, UK.

Ada Mau is Research Associate at University College London Institute of Education, London, UK.

Heather King is Lecturer in Science Education at King's College London, UK.

Spela Godec is Research Associate at University College London Institute of Education, London, UK.

Jennifer DeWitt is Research Associate at University College London Institute of Education, London, UK.

Emily Dawson is Lecturer in Science Education in University College London, Science \& Technology Studies. 


\section{Affiliations}

\section{Louise Archer ${ }^{1}$ D Effrosyni Nomikou ${ }^{1} \cdot$ Ada Mau $^{1} \cdot$ Heather King ${ }^{2} \cdot$ Spela Godec $^{1}$.} Jennifer DeWitt ${ }^{1} \cdot$ Emily Dawson $^{3}$

Effrosyni Nomikou

e.nomikou@ucl.ac.uk

Ada Mau

a.mau@ucl.ac.uk

Heather King

heather.1.king@kcl.ac.uk

Spela Godec

s.godec@ucl.ac.uk

Jennifer DeWitt

j.dewitt@ucl.ac.uk

Emily Dawson

emily.dawson@ucl.ac.uk

1 Department of Education, Practice and Society, UCL Institute of Education, University College London, 20 Bedford Way, London WC1H 0AL, UK

2 School of Education, Communication and Society, King's College London, Waterloo Bridge Wing, Franklin-Wilkins Building, Waterloo Road, London SE1 9NH, UK

3 Department of Science and Technology Studies, University College London, Gower Street, London WC1E 6BT, UK 